\title{
Exploring The Reasons Of Discontinuation Of Practicing Medicine Among Female Medical Students In Karachi
}

\author{
Nasreen Aslam Shah \\ Shagufta Nasreen \\ \& \\ Asma Manzoor \\ Women's Studies \\ University of Karachi
}

\begin{abstract}
From the late nineteenth century onwards, women in both industrial and nonindustrial countries have entered the most skilled and up to date branches of professions. The number has increased but in some fields women are dominating. The medical profession is one such field in which women are concentrated. The ratio is alike in Pakistan where girls dominate enrolment in medical colleges. More than $70 \%$ of students are females in medical colleges in urban areas especially Punjab and Sindh. Regrettably, not all of them end up practicing medicine. The objective of the study was to explore the reason for the high drop out. The study was conducted with a total 60 female medical graduates from different government and private hospitals of Karachi. Both qualitative and quantitative methods were used to do face to face interviews. The results show that most of them leave due to marriage and home responsibilities. The medical field has its own demands and to fulfill those responsibilities family, society and institutions have to help the woman medical profession to manage it. Otherwise, a human resource will be lost every year. It is also important to review the policies from time to time because to fulfill the needs of health services it is a reality that we need more doctors.
\end{abstract}

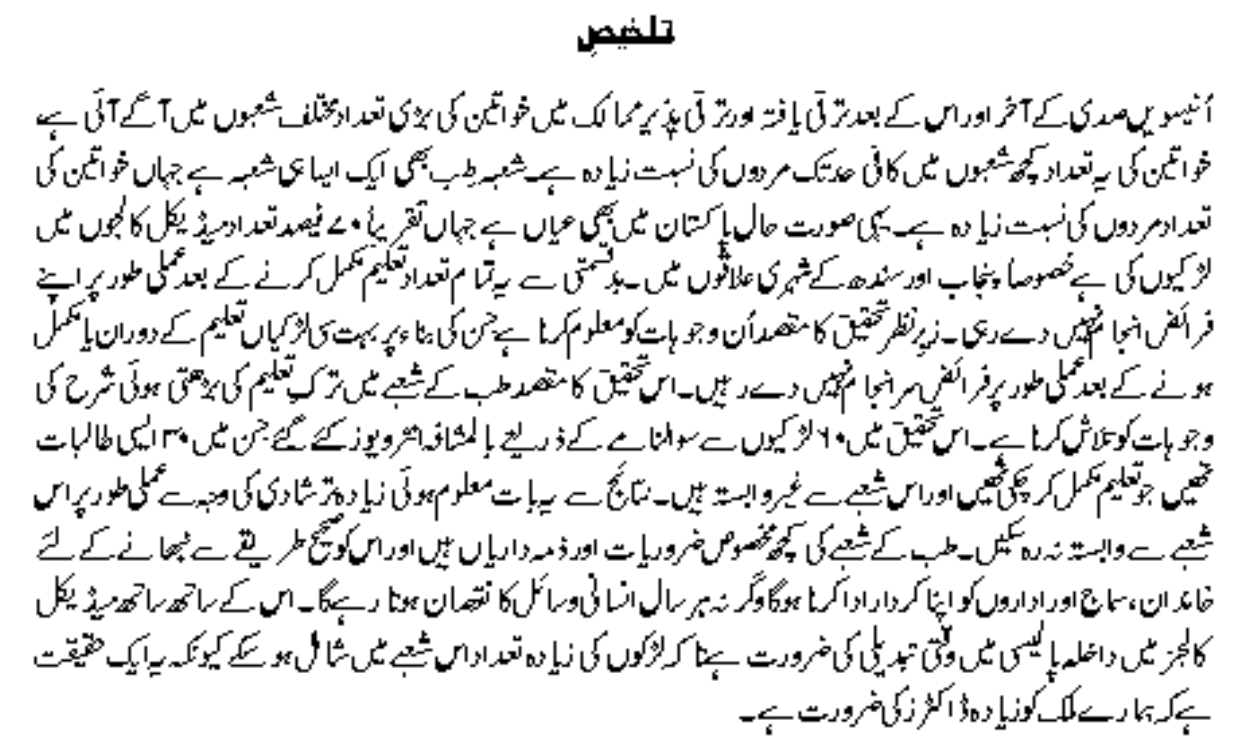


74 Exploring the Reasons of Discontinuation of Practicing Medicine among Female Medical Students in Karachi

Keywords: Female Medical Students, Reasons of Dropout, Gender Imbalance

\section{Introduction}

The status of women varies across classes, regions and cultures and rural /urban divide. Therefore, we see women in positions of Governor of State Bank of Pakistan, pilots, judges, police officers, army officers, athletes and world renowned artists and at the same time women face violence, discrimination and restrictions as well. Due to gender discrimination they are invisible in some fields and in majority in others, for instance labour force participation in Pakistan shows mostly women are found in service sector and mainly in the field of teaching and medicine. According to a recent report of Pakistan Employment Trends (2013), share of female employment in health and social work sector is $1.7 \%$ as compared to males which is $1.3 \%$. The ratio for female enrolment in medical colleges is high. ${ }^{1}$ According to a news report Pakistan Medical Association secretary general shared that 80 to $85 \%$ students of medical colleges are female especially in Punjab and Sindh while in Baluchistan and KPK men still outnumber women. ${ }^{2}$ Despite the large number of enrolment statistics shows that many of them discontinue the practice after completion of education. The objective of this paper is to analyze the reasons of drop out of female medical students between and after their studies.

While different form of healing methods have existed since humans began, but after the introduction of modern science allopathic form of medicine became the dominant. History shows that since the beginning of civilization medicine has been practiced almost exclusively by men. In Greece, at Hippocrates' time, women were always relegated to secondary importance. They were deemed incapable of carrying out medical activities; at most, they worked as midwives (Millan, 2009). Feminist argue that women practiced traditional medicine but as medicine, often crude and much worse than herbal remedies, became a male profession, they made efforts to de-legitimize women traditional practices and bar them from the new medical profession. Modern Medical knowledge is largely the result of men's pioneering work since the eighteenth century, a revolution paralleling those taking place in farming, industry and transport. Men therefore have dominated the work. From the late nineteenth century, however, women in both industrial and nonindustrial countries were entering the most skilled and up to date branches of the professions. In Europe and the United States, in colonial times, medical schools did not accept female students, although some of them worked as midwives or apothecaries. Harrier Hunt (1850 - 1875) was not allowed to attend medical classes in Boston and, after overcoming some obstacles she succeeded in getting a doctorate in Homeopathy. After being rejected by several schools, Elizabeth Blackwell (1821- 1910) was accepted to a small school in New York. Anticipating that her admission would be denied, the principal asked the students whether she should attend the medical course. Believing that it was a joke, the students gave their favorable opinion to it. The fact gave rise to an uprising in 
town. Blackwell could then attend the course, except for male reproductive system anatomy classes. She graduated two years later, in 1849. Her sister Emily also faced great difficulties, but together with other women she graduated from Cleveland school and was subsequently accepted by famous obstetrician James Simpson. In 1857, the Blackwell sisters and Marie Zakrzewska, a doctor from Berlin, founded a hospital for poor women and children in New York, which accepted female medical applicants (Millan, 2009).

Despite all difficulties, from the 50's the presence of women in medicine could be slowly but gradually noticed. In his literature review, De Angelis (1991) reported that in 1960 only $5 \%$ of physicians in the US were women. In the nineties, this number increased to $30 \%$. Female doctors' academic performance has usually been similar to male doctors'. They concentrate particularly in pediatrics (where they are majority), gynecologyobstetrics and psychiatry specialties. Only $4 \%$ of female resident doctors choose surgery. While $90 \%$ of the female population in the US is married, only $67 \%$ of female doctors are so. They divorce less when compared to the general population but twice as much as their male colleagues. Female doctors have later pregnancies and fewer children than the general population. Female doctors earn less money than male doctors. Their participation in academic life and scientific publications is smaller than men's. According to De Angelis (1991), Gordin et al. (1991), despite ongoing challenges, there are currently more women in medicine than at any point in history. They also note women frequently face discrimination in the profession and are overburdened with the responsibilities for raising children. Millan (2009) call our attention to the fact that women are promoted to the office of professor four times less than men. A survey conducted with medical students, assistant doctors and teachers showed that women think that their family commitments are a barrier to academic life. They receive less support from mentors over their professional life.

In previous centuries, health care had been provided by a range of itinerant and community-based healers, many of whom were women, and it was the elimination of these types of healers, together with the control of newly emergent ones, which were processes at the core of medicine's modern evolution (Larkin 1983). By the midnineteenth century, however, medical diagnosis and treatment had become the exclusive prerogative of medical men, and women had become restricted to the care of the sick, as nurses, and to the attendance of women during natural labour, as midwives. When the profession formally unified in 1858, male groups of physicians, surgeons and apothecaries were included whilst the female group of midwives was not (Verluysen 1980).So the history of the transition from the pre-modern to the modern practice of medicine is also the history of the restructuring of gender divisions in health care as women were excluded from certain spheres of competence and confined to others. 
76 Exploring the Reasons of Discontinuation of Practicing Medicine among Female Medical Students in Karachi

There were two key developments relating to the organization of medical practice which were at the core of the transition from pre-modern to modern medical practice and are of particular significance in charting the demise of female medical practice. The first has to do with changes in the market for medical services, and the second with changing forms of organizational control over medical practitioners.

In the Wall Street Journal, Josh Mitchell reported that "Women account for a third of the nation's lawyers and doctors, a major shift from a generation ago." The report was triggered by a new analysis of occupations from the Census Bureau, which showed women increased their share of doctor and lawyer by four percent and six percent, respectively, from a decade earlier. These professional advances mark "very significant progress," according to feminist economist Heidi Hartmann. She further agrees that it's a glass-half-empty perspective. But women are much more likely to drop out of these professions (and others). She quotes that among early-career professionals-people ages 25 to 44-who list their most recent jobs as doctor or lawyer, one can see that women are much more likely to be out of the labor force. ${ }^{3}$

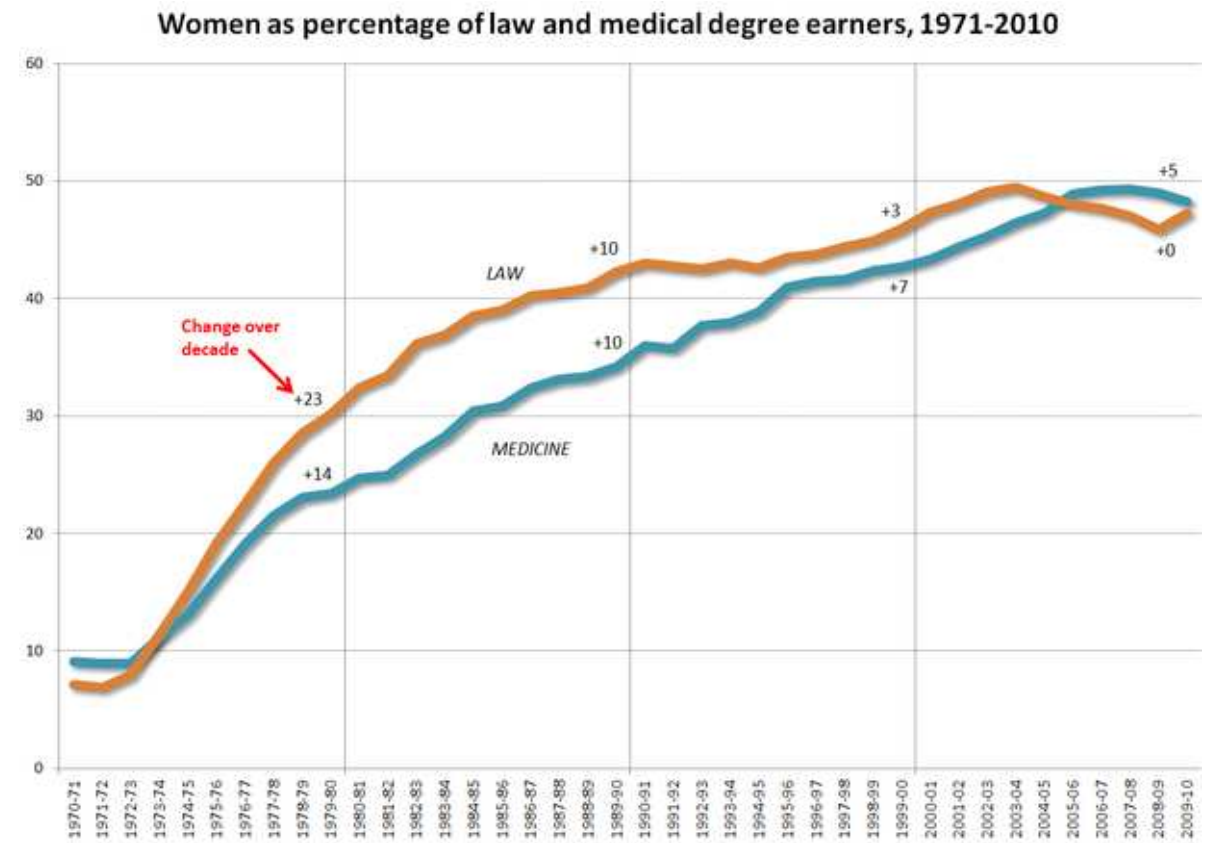

Source:http://www.theatlantic.com/sexes/archive/2012/12/more-women-are-doctors-and-lawyersthan-ever-but-progress-is-stalling/266115/

At the beginning of the twenty-first century in industrialized nations, women have made significant gains, but have yet to achieve parity throughout the medical profession. Women have achieved parity in medical school in some industrialized countries, since 2003 forming the majority of the United States medical student body. In 2007-2008, 
women accounted for $49 \%$ of medical school applicants and $48.3 \%$ of those accepted. According to the American Association of Medical Colleges (AAMC) 48.3\% $(16,838)$ of medical degrees awarded in the US in 2009-10 were earned by women, an increase from $26.8 \%$ in $1982-3 .^{4}$

The situation of Pakistan is also somewhat similar, where enrolment of female students has increased but many of them are not able to provide benefit to the nation. In 1991, the Supreme Court of Pakistan abolished the ratio of 60:40 for males and females and granted the admission on open merit. The interest of research was developed in this topic because as discussed in introduction on open merit female students were taking admission in medical schools but during studies or after completion many of them were not continuing the field of medicine. This situation may lead to restricting a quota of 50:50 percent justifying that women do not agree to work in rural areas or do not work after marriage thus wasting a seat. ${ }^{5}$

Karachi is the biggest city of Pakistan with a number of economic and educational opportunities for both males and females. In Karachi there is a large number of female engaged in higher education like medical, but many of these graduates do not continue it in future. Every year, thousands of women become doctors but only half of them practice. Research undertaken by the Sindh Health Department on five medical college shows that a total of 5,036 female students were enrolled in public sector colleges from the years $2005-2010$, but only around half of them, 2,518 students, were practicing doctors. ${ }^{6}$ The gender breakdown of doctors remains lopsided. According to another report, of the 132,988 doctors registered with the Pakistan Medical and Dental Council, 58,789 are women. The number of female specialists is even smaller: 7,524 out of $28,686{ }^{7}$ Despite the fact that the medical professions are among the most popular for women, researchers are concerned to know why so many female medical students drop out because of the consequences for the country's health care system.

This area of research has not gained attention of researchers that's why very few research studies mentioned this topic in their work. Rehman (et.al, 2011) explore about selection of field of specialty in medicine. The study shows that there are two most important reasons of drop out of doctors. Although the number of doctors is not increasing apart from increasing enrollments, for male doctors migration to other countries in search of better future prospects and discontinuation of practice after marriage for females. There are also cultural impediments. Women who do work often don't want to do so in rural areas far from their families or don't want night shifts, given the country's deteriorating law and order. Some male patients only want to be treated by men because they don't want women touching them or because they perceive the men to be smarter and more qualified. ${ }^{8}$ 
78 Exploring the Reasons of Discontinuation of Practicing Medicine among Female Medical Students in Karachi

\section{Methodology}

In this research the issue of high drop-out ratio among female medical students is analyzed. The study is an exploratory research with 60 female medical college graduates including 30 students who completed their studies and did not continue practice of medicine and 30 students who are studying now. Both qualitative and quantitative methods were used to prepare a questionnaire for ascertaining the students' socioeconomic profile- containing questions about gender, age, marital status, motivation of choosing medicine, opinion about suitability of medical profession for females, the influence of their marital status on their studies and its future implications. The universe of the study was 16 Medical Colleges based in Karachi including both private and public sector hospitals. The questionnaire was filled by face to face interviews. The data was converted into simple frequency tables to interpret the data.

\section{Results}

The study was to explore the reasons of high drop-out ratio among female medical college passed out and current students. Results showed that female students faced many problems during their studies. Table 1 shows that mostly those who left the medical field was due to marriage and taking care of home and children. They shared that they were very passionate when they joined the field. Unfortunately, it has become a status symbol for parents to enroll their daughters in medical colleges to find a future spouse for them. Once they find a good proposal their education becomes a secondary concern and parents pressurize them to get married and continue studies and practice later.

Table 1

Distribution of Respondents According to Reasons of Not Practicing Medicine

\begin{tabular}{|l|c|c|}
\hline Reasons of not Practicing Medicine & F & \% \\
\hline Due to family pressure & 2 & 7 \\
\hline Couldn't afford fees & 1 & 3 \\
\hline Got Married & 18 & 60 \\
\hline Taking care of home and children & 9 & 30 \\
\hline Total & $\mathbf{3 0}$ & $\mathbf{1 0 0}$ \\
\hline
\end{tabular}

Table 2

Distribution of Respondents According to their Feeling When They are Unable to Continue Practice

\begin{tabular}{|l|c|c|}
\hline Feelings after not Continuing Practice & F & \% \\
\hline Mentally disturbed & 18 & 60 \\
\hline Disappointed on destiny & 12 & 40 \\
\hline Total & $\mathbf{3 0}$ & $\mathbf{1 0 0}$ \\
\hline
\end{tabular}


Table 2 shows that it leaves them mentally disturbed because they are unable to achieve their goals, while $40 \%$ blamed their destiny of being female. They thought it was not in their control to decide about it.

Table 3

Distribution of Respondents According to Reaction of Family and Friends When They Heard about their Decision Leaving Medicine

\begin{tabular}{|l|c|c|}
\hline $\begin{array}{l}\text { Reaction of Family and Friends } \\
\text { after not Continuing Practice }\end{array}$ & F & \% \\
\hline Normal & 14 & 47 \\
\hline Not happy & 03 & 10 \\
\hline $\begin{array}{l}\text { They blamed that a medical } \\
\text { student seat is wasted }\end{array}$ & 13 & 43 \\
\hline Total & $\mathbf{3 0}$ & $\mathbf{1 0 0}$ \\
\hline
\end{tabular}

Table 3 shows that $47 \%$ said their family reaction were 'normal' i.e. parents were generally satisfied when their daughters dropped out, when they left the field. It shows that people mostly believe that primary responsibility of females is marriage and taking care of home and children. While $43 \%$ thought that if they were not able to continue their profession it will be lost of resources. General perception about female students who do not practice has gained a strong resentment among male students due to this notion.

Table 4

Distribution of Respondents According to their Views about Reasons of Female Drop out in their Opinion

\begin{tabular}{|l|c|c|}
\hline Opinion about Drop out of Females & F & \% \\
\hline Due to family or social pressure & 6 & 10 \\
\hline Due to marriage or marital responsibilities & 46 & 76 \\
\hline Male Dominance & 1 & 1.5 \\
\hline Girls are sensitive & 4 & 6.5 \\
\hline Women lack job attitude & 3 & 6 \\
\hline Total & $\mathbf{6 0}$ & $\mathbf{1 0 0}$ \\
\hline
\end{tabular}

The question of reasons of drop out of female medical students was asked from all 60 respondents and $76 \%$ had confirmed the point of view that it was marriage and its responsibilities which was a major cause of it. However, they also mentioned about girls attitude that they don't want to continue job. 
80 Exploring the Reasons of Discontinuation of Practicing Medicine among Female Medical Students in Karachi

Table 5

Distribution of Respondents According to Who Suggested to Join Medicine

\begin{tabular}{|l|c|c|c|c|}
\hline Who Suggested to Join Medicine & \multicolumn{2}{|c|}{ Practicing Medicine } & \multicolumn{2}{c|}{ Non-Practicing } \\
\hline & $\mathrm{F}$ & $\%$ & $\mathrm{~F}$ & $\%$ \\
\hline Father & 12 & 40 & 13 & 44 \\
\hline Decided by themselves & 15 & 50 & 11 & 36 \\
\hline Friend & 1 & 3 & 1 & 3 \\
\hline Mother & 2 & 7 & 5 & 17 \\
\hline Total & $\mathbf{3 0}$ & $\mathbf{1 0 0}$ & $\mathbf{3 0}$ & $\mathbf{1 0 0}$ \\
\hline
\end{tabular}

Interestingly, when they were asked about their motivation of joining this field, $50 \%$ current students said it was their own decision, and second highest rate was where decision was made by fathers. Those who discontinued after marriage in them majority decision makers were fathers followed by mothers and only $36 \%$ decided by themselves. This also shows the lack of interest in the beginning of the field.

Table 6

Distribution of Respondents According to Restart your Profession

\begin{tabular}{|l|c|c|}
\hline Restart your Profession & F & \% \\
\hline Yes & 17 & 57 \\
\hline No & 13 & 43 \\
\hline Total & $\mathbf{3 0}$ & $\mathbf{1 0 0}$ \\
\hline
\end{tabular}

Majority non-practicing graduates said they wish to continue practice in future. All of them thought that medicine is a suitable profession for females but managing home, children and job becomes difficult.

\section{Discussion}

The purpose of this research was to find out the extent of gender inequality or imbalances among medical students. In Pakistan, women constitute half of population and they always threaten in terms of culture and social pressures. Although, in urban areas, girls have access to all kind of educational opportunities but socio-cultural restrictions play an important role in shaping their lives and their choices. The situation has changed a lot in the last two decades but the transition is creating some new problems as well. Women are entering in formal and informal employment but they are expected to fulfill their household responsibilities as well. This job, family and other activities create triple burden on them. Generally people have different views about this situation. Traditionalist suggests that it was better for women to fulfill household responsibilities modern society has increased burden on them. Modernists give the examples of Western world and suggest that women should be highly educated and should take part in every field. In the 
beginning of article, studies from developed countries shows that to some extent, female doctors face problems related to marriage and family life. But they have been able to manage it comparatively, because whenever women workers are facilitated with maternity benefits, child care facilities and share of work at home with other family members. In Pakistan a large number of women have become part of formal and informal sector jobs but they are struggling for decent work.

The decision of open merit admission for medical college students resulted in a dominance of enrollment for girls in medical colleges which was a positive step. But the high ratio of discontinuation of practice after completing their education has become a debate to revise this decision or to establish medical colleges only for men to fulfill dearth of doctors in the country. In Karachi, there is large number of women enrolled in medical colleges but not all of them are continuing to work because of pressure of families to get married and difficulties in managing job and home after marriage. Every year thousands of women become doctors but half of them practices as doctors. It adversely effects our economy as well as our institutes.

\section{Conclusions}

The research found out there was imbalance and gender in-equality in medical profession in Pakistan. It was also found that the major reason of drop out of females was marriage and marital responsibilities and it caused females to quit their medical profession. Females do not drop out their studies; they usually drop out because of double burden of work i.e. family responsibilities and professional responsibilities. Medical field has its own demands and to fulfill those responsibilities; family, society and institutions has to help to her manage it. Otherwise, a human resource will be lost every year. It is also important to review the policies from time to time because to fulfill the needs of health services it is a reality that we need more doctors. Therefore, it is necessary to take suggestions from stake holders and revise the admission policy of medical colleges.

\section{End Notes}

1. Pakistan Employment Trends, 2013. http://www.pbs.gov.pk/content/pakistanemployment-trends-2013

2. http://www.dawn.com/news/803667/pakistans-medical-schools-where-thewomen-rule

3. More Women Are Doctors and Lawyers Than Ever-but Progress Is Stalling http://www.theatlantic.com/sexes/archive/2012/12/more-women-are-doctors-andlawyers-than-ever-but-progress-is-stalling/266115/ 
82 Exploring the Reasons of Discontinuation of Practicing Medicine among Female Medical Students in Karachi

4. https://www.aamc.org/members/gwims/statistics/

5. http://www.huffingtonpost.com/2013/04/19/pakistani-women-vast-majoritymedical-school_n_3115776.html

6. http://tribune.com.pk/story/315244/women-doctors-financial-cost-of-social-hangups/

7. http://www.dawn.com/news/803667/pakistans-medical-schools-where-thewomen-rule

8. http://www.huffingtonpost.com/2013/04/19/pakistani-women-vast-majoritymedical-school_n_3115776.html

\section{References}

De Angelis, C. (1991). Women in Medicine, A.J.D.C., v.145, p.49-52.

Goldberg, I. (1995). Doctors and their Careers, British Journal of Hospital Medicine, v. 53, no.11, pp. 545-46.

Gordin, R., Jacobsen, S.J. \& Rimm, A.A. (1991). Similarities in the Personalities of Women and Men who were First Year Medical Students Planning Careers as Surgeons. Academic Medicine, v. 66, n. 9, p. 560.

Larkin, G. (1983). Occupational Monopoly and Modern Medicine, London, Tavistock.

Millan, Luiz Roberto. (2009). Medical Career Choice: A Gender Study, NY, USA: Nova Science Publishers, Incorporated.

Rehman,A (et.al) (2011) Pakistani Medical Students' Specialty Preference and the Influencing Factors, http://www.ncbi.nlm.nih.gov/pubmed/22204259

Verluysen, M. (1980). Old Wives Tales? Women Healers in English History' in C.Davies (ed.) Rewriting Nursing History, London: Croom Helm.

Witz, Anne, (1992). Professions and Patriarchy, London, GBR: Routledge. 
Dr. Nasreen Aslam Shah is Meritorious Professor in the Department of Social Work and Director, Centre of Excellence for Women's Studies, University of Karachi.

Dr. Shagufta Nasreen is Teaching Associate in the Centre of Excellence for Women's Studies, University of Karachi.

Dr. Asma Manzoor is Teaching Associate in the Centre of Excellence for Women's Studies, University of Karachi. 